\title{
Face to face with babies
}

\section{P. E. Bryant}

Most theories of perception used to depict young babies as perceptual incompetents, capable of discriminating little and of recognizing even less. Now psychologists are more likely to speak with awe than with contempt about the perceptual feats of neonates, and a paper by Johnson et al. ', which appears in the latest issue of Cognition and deals with their attraction to human faces, serves as a striking reminder of how impressive their accomplishments are.

Nearly all recent studies of perception in young babies stem from the preference method invented by Robert Fantz ${ }^{2}$. Fantz argued that, if you want to know whether infants see the difference between a pair of shapes, you should show them the two and if they consistently look at one for a longer time than at the other they must at some level have perceived the difference between the two. This method, and a subsequent refinement of it called the habituation paradigm', were a considerable success, and it is now clear that babies make many quite impressive discriminations from a very early age.

One, almost incidental, advantage of the preference method is that it also tells us a great deal about what babies like. as well as about what thev can discern. The most riveting pattern for them seems to be a regular checkerboard. This dreadfully boring motif probably captivates the young infant because it contains a great deal in the way of contour and thus in the quantity of stimulation that it offers the infant.

Another, slightly less consistent, source of attraction for infants is the human face. In an ingenious, mobile version of the preference method, Goren and colleagues" put various patterns, one at a time. in front of very young babies and then moved each pattern to one side: they reported that neonates followed the movement of a face-like pattern with more persistence than they did a pattern made from features of the face arranged in a random and definitely non-face like way (a 'scrambled face'). But it now seems evident ${ }^{+}$that in their first month babies show no preference for looking at schematic faces rather than at 'scrambled' faces when these are presented statically, although twomonth-old babies do.

The main aim of Johnson et al. was to explain why very young babies look longer at faces than at scrambled faces when the displays are moved, and yet apparently have no strong preferences of this sort when looking at static patterns. In two separate experiments, the authors replicated the results of Goren et al.'s study. But the result by which Johnson et al. set most store, and which is their novel contribution, came from a third experiment which involved older babies who were one, three or five months old. This was also a tracking experiment, but it took a different form: this time the schematic face or the control patterns stayed in the same place and the babies were moved around the pattern in front of them. (The experimenters were forced to make this change because they found that the Goren procedure was not
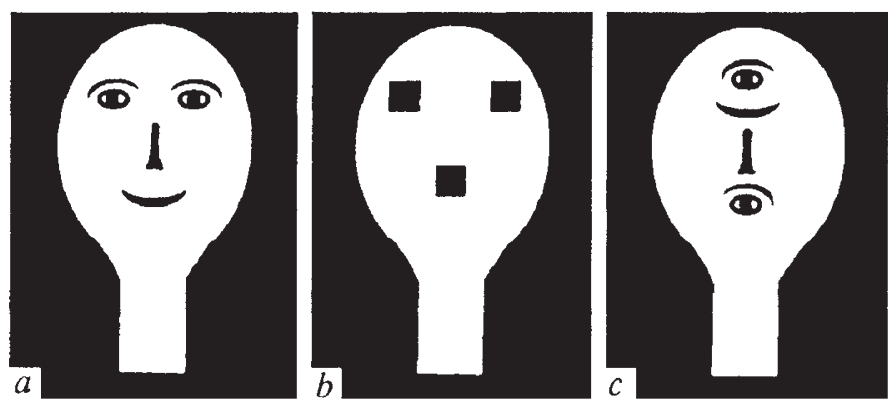

Examples of stimuli used in experiments by Juhnson and Morton. $a$, Face with all the right components in the right places. $b$, Face with the right arrangement but incorrect details. $c$, Linear face. d. Scrambled Face. (Taken from ref. 5.)

a success with the older infants.) Again, the question was whether babies would continue to look at the face longer than at the other patterns, and the answer in many ways a surprising one - was that the one-month-old babies did but the older babies did not.

So, the story that Johnson and his colleagues tell is that babies of all ages prefer to look at human faces rather than at comparable patterns, but that the way that they show this preference is quite different at different ages. The authors' explanation for this developmental change is largely neurological. They appeal to the immaturity of the human visual system (particularly of the cortical visual pathways) at birth, and they argue that the preference for tracking mobile faces happens at a time when the babies' vision is largely under the control of subcortical mechanisms. Once the cortex takes over, the preference switches to a static one. This hypothesis is presented rather cursorily in the paper in Cognition, but is given a more expansive and comprehensible treatment in a new book ${ }^{5}$ by two of the paper's authors.

The hypothesis is a provocative one and raises many questions. One concerns the one novel result on which the hypothesis is based - the finding that one-month-old babies keep their eyes fixed on a face for a longer time than on any other comparable pattern when they

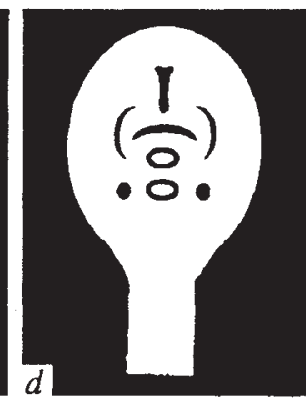

(the babies) are moved around the pattern, whereas older babies show no such preference. Although I can see why a more primitive visual system might function more effectively with a moving than with a static display, I cannot understand or find any explanation in the paper as to why older babies, which have more sophisticated mechanisms, should fail to track a face with particular persistence when they are moved around it. One mundane possibility, which is not part of the authors' scheme but does not seem to be ruled out by their data, is that the older children, now equipped with more powerful visual mechanisms, realize that the 'face' in question is not a real one and therefore do not bother to keep on looking at it when they are moved on.

Another difficulty, as far as I am concerned, is that there are other studies in which neonates have shown striking visual powers when confronted with static faces. One of these is a remarkable demonstration that neonates (only two days old) prefer to look at their mother rather than at another unknown woman ${ }^{6}$. So young babies" neurological mechanisms, however incomplete, do not prevent them from making some powerful discriminations about static human faces. Perhaps the restriction of preferences to moving displays in the early months applies only to schematic faces. We need more evidence on babies' preferences for real faces. Of course it is harder to provide the proper controls in a study with real faces: how do you scramble a real face? But such controls cannot be beyond the ingenuity which has always been the hallmark of research on infants" perception.

P. E. Bryant is in the Department of Ex perimental Psychology, University of Oxford. South Parks Road, Oxford OX1 3UD, UK.

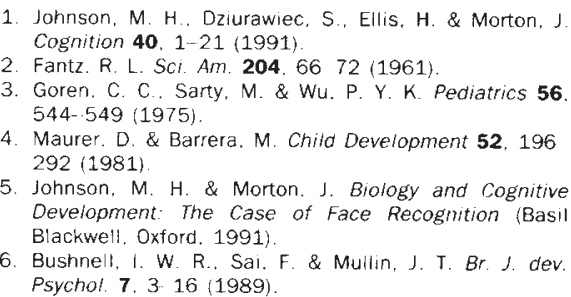

Johnson, M. H. \& Morton. J. Biology and Cognitive Development: The Case of Face Recognition (Basil Blackwell. Oxford. 1991)

6. Bushnell, I. W. R.. Sai, F. \& Mullin, J. T. Br. J. dev Psychol. 7. 3. 16 (1989). 